\title{
REVIEW
}

\section{Understanding Policy Success: rethinking public policy}

\author{
Allan McConnell \\ Basingstoke: Palgrave-Macmillan, 2010, 265pp, £22.99 (pbk) \\ ISBN 9780230239753 \\ Tony Gore* \\ Sheffield Hallam University
}

The rumblings in the UK over public expenditure cuts, efficiency savings, eliminating 'waste' and achieving value for money were in full swing when this book landed on my desk. Its theme of Understanding Policy Success appeared to be a perfect fit with the prevailing political climate, and I was keen to find out what it had to offer in getting to grips with the varied changes and complex manoeuvrings of present times. As will be revealed, this hope was only partially fulfilled, but at the same time I was glad to gain familiarity with a well-argued and systematic examination of the public policy process, and some of the key requirements for assessing its outcomes and impacts. In this sense this book will have appeal across its intended audience of public policy scholars and practitioners.

The aims of the book are quite ambitious. They are:

"...to provide a framework that allows us to explore (the) puzzling phenomenon (of policy success) in a way that has hitherto been almost absent in public policy literature....(and) to use this framework to rethink established models of how public policy is understood." (p.4)

The starting point for this is a review of the three main ways of conceptualising public policy, namely in process, programme or political terms. As a marker of the essentially eclectic approach employed throughout the book, the author then draws these together as the first strands of a multi-dimensional model. Further examination of the literature then follows, this time on the more specific topic of 'policy success'. McConnell identifies two main perspectives: the 'foundationalist' view that emphasises success as fact (i.e., achieving intended goals); and the 'anti-foundationalist' view that success is all in the eye of the beholder (i.e., the interpretation of results according to one's viewpoint and values). Not surprisingly, the conclusion is that both have merit, and that policy analysis should incorporate both in a more 'realist' framework. This is then linked to the three strands of the public policy model to define a set of key criteria by which success in each might be measured. For example, 'process' success includes 
ensuring policy legitimacy; 'programme' success includes producing desired outcomes; and 'political' success includes enhancing electoral prospects.

Chapter 3 adds a further layer by picking apart the complex space between the extremes of 'success' and 'failure', arguing that there is a spectrum of more nuanced 'in-between' states, such as 'durable success' and 'precarious success'. After each of these is defined, they are ranged against the key measurement criteria of the three public policy strands (process, programme, politics). This gives rise to a series of detailed matrices in which are outlined the policy outcomes that arise when the different combinations come together. Real life examples are also quoted to illustrate these features. These include the ban on wearing headscarves by Muslim women in France, and a micro-finance initiative in Bangladesh. Issues surrounding the identification and measurement of policy success are then explored in Chapter 4. This revisits well-known themes such as choice of metrics (and whose interests different ones might serve); attribution and deadweight (although these terms, common in evaluation circles, are not used); data verification; capture of unintended consequences; and temporal and spatial contexts. These deliberations are then condensed into a very useful 10-point framework of questions and issues to be addressed in assessing whether or not a policy has been successful.

The approaches and actions of political actors and other interested parties provide the focus for the next section of the book. First, the way that policy success (or failure) is framed (and on whose terms) is examined, tracing the adoption of different baselines, claims and counter-claims according to changing circumstances and viewpoints, and the varying narratives and discourses that accompany these shifts. A set of nine 'bases of claim' to success is identified; these include some of those already articulated, such as meeting objectives or beneficial outcomes. However, McConnell also takes the opportunity to extend the framework by incorporating further mechanisms, such as benefits exceeding costs, comparison with other jurisdictions and moral imperatives. In some ways this discussion would have worked better if it had come earlier, given the clear connections between types of claim and the measurement issues explored in the previous chapter. As it is, these remain generally implicit.

Chapter 6 takes the analysis forward by developing another framework, this time as a means for understanding the range of strategies deployed by policy officers and political actors in producing 'successful' policy, and the contextual considerations that influence when particular strategies might be most appropriate. Options include striking deals, selective use of evidence, extensive and/or directed consultation, and importing ideas from other jurisdictions. Choice of strategy is seen to be related to the degree of risk involved in using that one, as opposed to alternatives. Alternative strategies and varying risk levels are then ranged against each other in a matrix and their implications summarised. This is followed by a demonstration of how the matrix can be applied to particular cases (the examples here being gun control reform in Australia; and poll tax introduction and removal in the UK).

A fourth framework is developed in Chapter 7 , this time to aid understanding of different elite strategies in shaping policy evaluations (i.e., a key way of assessing 'success'). A threefold typology of approaches (tight, relaxed and loose grip) is used to highlight the varying formats, parameters, timescales, timings, methods, questions and reporting styles found across the evaluation spectrum. Attention is also given to the decision-making process involved in choosing evaluators, and to the management of the process during its course. This inevitably entails a review of steering mechanisms, such as recommendation or prohibition on who is consulted, publication or nonpublication of reports and selective use of evaluation evidence. 
p.48. Review: Understanding Policy Success: rethinking public policy

The substance of the book is rounded off by a series of reflections on the conditions for cultivating and sustaining policy success, and means by which others can learn from or predict it. The counter arguments that such conditions are either universal (following principles such as privatisation) or contextual (always needing to respond to specific circumstances) are rejected in favour of a more middle-ground 'familial' approach. This contends that there are shared or similar contexts in which a given policy action would have less risk of failure than in others. Conditions for sustainable policy success are also rehearsed, including factors such as path dependency, stable value orientations, cross-party agreement, and absence of viable alternatives.

The final part makes a series of claims about the 'policy success' approach. To begin with, the author sees it as a way of revealing processes and dynamics in the 'dark corners' of policy-making that analysts are seldom able to capture. He also states that it can be used as an 'add-on' to existing approaches to policy analysis like the rational choice and new institutionalist paradigms. Finally, not content with this, the set of frameworks developed in the book are billed as much more than this, as:

"....a new model of the policy process, with....better explanatory power than the policy cycle (model) and....the capacity to explain policy outcomes with just as much credibility as mainstream models." (p.9)

However, which mainstream models McConnell has in mind are not divulged. Devising improvements to the rather simplistic policy cycle approach may not be that much of a big deal either. Although I am not familiar with the full gamut of political science and policy analysis literature, I do know that the body of writings on how policy is formed and implemented is a formidable one. In this light, it would seem that there is a great deal here that is fairly commonplace. While the author has done an excellent job in drawing lots of strands together in the same place, and in placing it in a series of very useful frameworks, nevertheless there appear to be several gaps and flaws in the material presented.

One of these concerns the well-known concept of implementation gaps. Although the text does quote Pressman and Wildavsky's seminal paper (1973), little space is given over to the extensive work that has ensued on the topic. Related to this is the rather one-dimensional view of government implicit throughout. On the one hand it is assumed to be an elected body, and on the other it appears to denote national government. This means that the approach not only rests on a rather narrow interpretation of politics, but also ignores the key role of sub-national units and inclusive partnerships in influencing and implementing policy. These seem to be significant omissions, given the copious literature on the switch from government to governance and the growing influence of interest groups, advocacy coalitions and policy networks. Although the importance of spatial contexts is emphasised, there is little attention paid to how policy filters between different tiers in a national (or even supranational) polity, as exemplified by the now extensive writings on multi-level governance.

Similarly, for those with knowledge of the wide-ranging academic and practical literature on evaluation approaches and techniques, the book may not live up to expectations. Certainly, the very title of the book, Understanding Policy Success, would appear to merit more detailed exploration of exactly how all those thorny issues around measuring 'success' and managing the politics of evaluation can and have been dealt with. Presumably the level of detail required may have persuaded the author that this was far beyond the remit he had set himself, but such additions would surely have enriched the overall approach being developed. Certainly dealing with attribution, additionality and admissible evidence in just three pages begs the question whether 
p.49. Review: Understanding Policy Success: rethinking public policy

the frameworks provided in the book would be sufficient to ascertain for definite whether or not 'success' had been achieved, and whether the policy initiative in question could claim responsibility.

Without these elements, the approach developed in the book becomes more of a tool for detailed, in-depth descriptive analysis. In these terms, as already acknowledged, the various frameworks offered for examining various aspects of the policy process are comprehensive and valuable. Ultimately, however, the book's claim to explanatory power founders on the lack of an explicit theoretical stance, particularly in terms of the relationships between the state and society, and the role of policy in mediating them. The eclectic approach of steering a mid-course between opposing positions, while attractive at first sight, leads to some confusion as to exactly what the base principles of the argument are.

Moreover, the insistence that analysis should be conducted using matrix-based frameworks might bring consistency to the treatment of different cases, but it does bring with it a certain rigid stylisation in what is presented. Claiming that the framework can be bolted on to approaches as theoretically disparate as rational choice and new institutionalism likewise sets the alarm bells ringing. In sum, the 'policy success' model offers lots of good ideas about how to initiate enquiries about policy development and implementation, and has the potential to reveal surface aspects of policy shifts such as the current 'deficit reduction' mantra, but for me it is difficult to see how it would lead to deeper answers to root questions about the provenance of such policies, or their unequal implementation and impacts.

*Correspondence address: Centre for Regional Economic and Social Research, Sheffield Hallam University, City Campus, Sheffield S1 1WB . Email: t.gore@shu.ac.uk

\section{Reference}

Pressman, Jeffrey and Wildavsky, Aaron (1973) Implementation. Berkeley: University of California Press. 